\title{
Nanomaterials: Applications in Electronics
}

\author{
Harshada V. Mhetre, Yuvraj. K. Kanse, Suhas. S. Patil
}

\begin{abstract}
Nanotechnology is steadily transgressing from the laboratory to the commercial sphere and is enhancing products in a variety of sectors. Nanotechnology $R \& D$ has evolved from foundational discoveries aimed at understanding and exploiting nanoscale behaviour to an enabling technology. Nanomaterials are materials which are sized between 1 to $100 \mathrm{~nm}$. Due to the basic characteristics of nanomaterials such as optical properties, reflection, transmission, absorption, and light emission, which are different from those of bulk materials, nanomaterials are useful in a variety of applications in different fields. In this paper the different types of nanomaterials have been outlined based upon their dimensions and applications in the field of electronics such as Quantum dots (QD's) in solar cells and Carbon Nanotubes and graphene in FETs.
\end{abstract}

Keywords: Quantum dots, carbon nanotubes, graphene, solar cells, FETs

\section{INTRODUCTION}

$\mathrm{N}$ anomaterials are defined as "a natural, incidental or manufactured material containing articles, in anunbound state or as an aggregate or as an agglomerate and where, for $50 \%$ or more of the particles in the number size distribution, one or more external dimensions is in the size range $1 \mathrm{~nm}-100 \mathrm{~nm}$ ". This definition was adopted by the European Commission on 18 Oct 2011. The nanomaterials have optical properties like transmission, absorption, reflection and light emission, which are different from that of the bulk materials thereby rendering its significant usefulness in different fields. Nanomaterials are used in next generation electronic devices, high energy density batteries \& magnetics, long lasting medical implants, ductile machinable ceramics \& high-grade insulation, satellites \& aerospace engineering components, clothing, cosmetics industry and clean energy technology amongst other areas.[91][92].

The dimensional classification is used to categorise nanomaterials as follows:

1) OD materials where in all dimensions are in nanoscale $1-100 \mathrm{~nm}$.

2) 1D material wherein one dimension is outside nanoscale

3) $2 \mathrm{D}$ wherein two of the dimensions are outside anoscale and

4) $3 \mathrm{D}$ wherein the bulk nanomaterials are not in nanoscale in any dimensions

Manuscript received on August 24, 2021.

Revised Manuscript received on September 24, 2021.

Manuscript published on September 30, 2021

* Correspondence Author

Mrs. Harshada V. Mhetre*, Research Scholar Student, Department of Electronics Engineering, Bharati Vidyapeeth University, Pune (Maharashtra), India.

Dr. Yuvraj K. Kanse, Department of Electronics Engineering, Shivaji University, Kolhapur (Maharashtra), India.

Dr. Suhas S. Patil, Department of Electronics Engineering, Shivaji University, Kolhapur (Maharashtra), India.

(C) The Authors. Published by Blue Eyes Intelligence Engineering and Sciences Publication (BEIESP). This is an open access article under the CC BY-NC-ND license (http://creativecommons.org/licenses/by-nc-nd/4.0/)

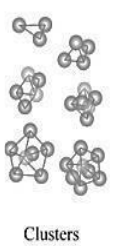

OD

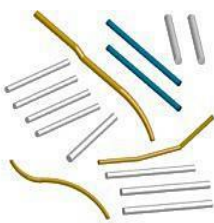

Nanotubes, fibers and rods

1D

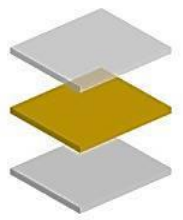

Films and coats

$2 \mathrm{D}$

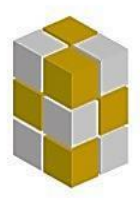

Polycrystals

$3 \mathrm{D}$
Fig. 1 Classification based on dimensions.[115]

\section{DIMENTIONAL}

\subsection{Quantum Dots}

Quantum dots also called artificial atoms are zero-dimension particles in nanomaterials. These particles being in the nanometer range presents different electronic and optical properties as compared to their bulk material properties. The wavelength of light emitted by the quantum dots depends on their size wherein the blue and green colour of short wavelength and the red and orange colour of long wavelength are observed to be emitted by QDs of 2-3 Nm and 5-6 Nm respectively.

\subsection{Synthesis Processes:}

General techniques for quantum dot synthesis are top-down processing method and bottom-up approach.

\subsection{Top-down processing methods:}

As brought out by Valizadeh et al, "these include molecular beam epitaxy (MBE), ion implantation, e-beam lithography, and X-ray lithography. To achieve QDs of diameter approximately $30 \mathrm{~nm}$, electron beam lithography, reactive-ion etching, and/or wet chemical etching are commonly used" [ 29,103].

QDs have also been fabricated using laser beams/ focused ion. However, QDs arrays fabricated through these processes have shown certain structural imperfections and impurity content $[1,103]$.

\section{a. Bottom-up techniques:}

The bottom-up technique includes the wet chemical and vapour phase methods for QD synthesis [1, 104].

As per Valizadeh et al [103], "wet-chemical methods are generally microemulsion, sol-gel, competitive reaction chemistry, hot-solution decomposition, sonic waves or microwaves, and electrochemistry".[2-4, 5-7,8] These processes are based on the method of precipitation for single/ mixture of solutions under controlled parameters. The QD production in vapour phase method uses atom-by-atom growth of layers which is followed by self assembly of QDs on a substrate [9-12, 103]. As per Bera et. al., "self-assembly of nanostructures in material grown by MBE, sputtering liquid metal ion sources, or aggregation of gaseous monomers are generally categorized under vapour-phase methods" [104].

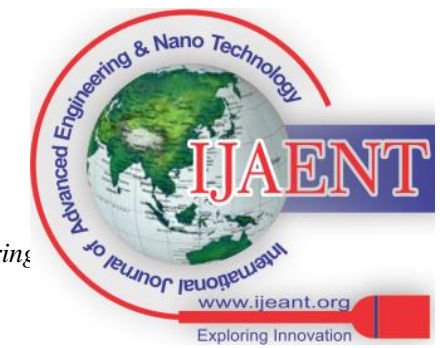




\section{Nanomaterials: Applications in Electronics}

\section{b. Hot injection method:}

The hot injection is the predominantly used synthesis process for production of high quality QDs [ 106]. Several articles have been published reviewing the advantages of this process $[13,105]$. However, a major disadvantage of this reaction method as observed in the reaction container of larger volume is the practical difficulty to achieve an instant homogeneous reaction.

\section{c. Non injection methods:}

It has been reported that using this method of synthesis nanocrystals of CdSe and CdTe of sizes within 5\% standard deviation can be produced [14,15, 106]. This process of synthesis produces CdSe nanocrystals with zinc blende structure and a PL quantum yield of 30-40 \% [14,15, 106]. By using processes similar to the non-injection approaches various families of II-VI binary and ternary magic-sized nanocrystals (MSNs) have also been developed by Yu et.al [16-22, 106]. The core-shell configuration and single sized nature of the magic-sized nanocrystals are thermodynamically better with extremely narrow absorption/emission width making it an attractive choice for applications like solid-state lighting and telecommunications [106].

Non-injection synthesis method has also been used to produce ternary systems like CdTeSe magic-sized nanocrystals and CdSeS regular nanocrystals [106].

d. Solvo thermal method or hydrothermal method (in aqueous medium)

Though this method has been used to synthesise semiconductor quantum dots this has been largely restricted by the inferior product properties as per Hu et. al [106].

e. $\quad$ Microwave and flow through processes:

This may be a possible approach towards large scale synthesis of semiconductor nanocrystal quantum dots as it features simple operation [23]. Producibility of high-quality nanocrystal of the colloidal semiconductor variety is possible using microwave synthesis in organic and aqueous media [106].

\subsection{Applications of QDs:}

\section{a. Solar Cells:}

Burnham and Duggan were the pioneers to conceive the use of QDs for high efficiency solar cells in 1990. A large variety of solar cells have been developed over the past few decades. The high-performance solar cells of crystalline silicon and GaAs materials and the thin film solar cells made from CdTe and CIGS materials are constrained by the higher material and fabrication costs while Cadmium and telluride are rare and highly toxic metals [106]. On the other hand, dye-sensitized and organic solar cells have the advantage of higher flexibility and lower production cost.

Schaller et. al., in 2004, reported "spectroscopic evidence that several excitons could be efficiently generated upon absorption of a single energetic photon in a quantum dot, an approach now known as CM (carrier multiplication) or MEG (multiple exciton generation)" [107]. "This property boosts the energy conversion efficiency beyond the traditional Shockley and Queisser limit for silicon solar cells [24] through increased photocurrent. LANL's dots were made from PbSe." As per Hu et. al., "three types of solar cells have been reported in this category [106]:
i)Quantum dot/metal Schottky junction solar cell ii) Polymer/ quantum dot hybrid solar cell

iii)Quantum dot/ quantum dot D/A solar cell"

$\mathrm{Hu}$ et al has brought out that many QD solar cells with Schottky junction structure have been reported based on $\mathrm{PbS}$ [25,26], PbSe [27], and $\mathrm{PbS}_{\mathrm{x}} \mathrm{Se}_{1-\mathrm{x}}$ [28] nanocrystal systems which hold the capacity to utilize the infrared part of the solar energy because of the small bandgap of the nanocrystals which leads to a power conversion efficiencies of $2.1 \%$ for PbSe [27], $2 \%$ for PbS [26], 3.3\% for $\mathrm{PbS}_{\mathrm{x}} \mathrm{Se}_{1-\mathrm{x}}$ based devices and monochromatic power conversion efficiency (MPCE) of $4.2 \%$ [28]. Various processes like the layer-bylayer dip coating [26,27]and spin coating [25] are employed for fabrication of the nanocrystal layer using P3HT / MEHPPV as the active polymer mixture layer to enhance electron transport, light harvesting and performance [106]. In order to ensure that the exciton reach the donor and acceptor, the domain lengths and exciton diffusion length should be of comparable magnitude. A higher power conversion efficiency has been reported by using a combination of CdSe nanorod and P3HT.

Polymer/organic materials have problems of stability which can be overcome by developing pure inorganic QDSC. Alivisatos worked using a " $\mathrm{CdSe} / \mathrm{CdTe}$ nanorod system and a bilayer heterojunction structure, devoid of organic materials, reporting improved atmospheric stability and $2.9 \%$ power conversion efficiency"[30].

It has also been observed that sensitisation of solar cells using QDs gives improved power conversion efficiency as reported in the case of " $\mathrm{TiO}_{2}$ solar cell sensitized with CdSe with a cobalt (II/III) based redox system" [31,32].

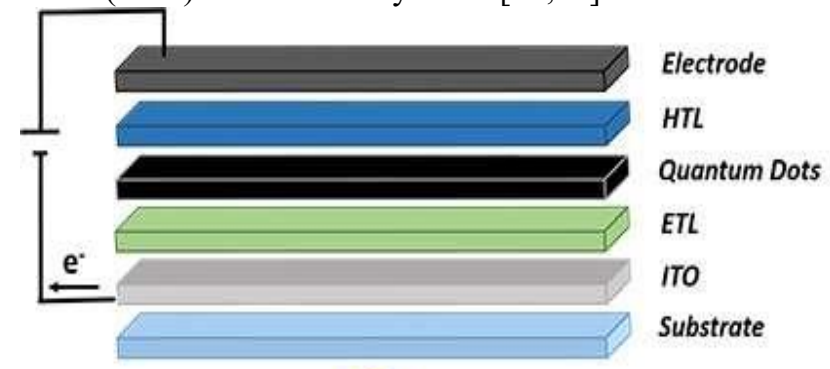

Fig 2: Arrangement of QD Solar Cell taken from [48]

Advantages of using QDs in solar application: QDs combines the benefits of inorganic and organic materials. Devices incorporating QDs have the following advantages:

(i) low cost

(ii) solution-based

(iii) enhanced charge separation efficiency

(iv) higher PL quantum efficiency

(v) better chemical stability

(vi) covers infrared spectrum

(vii) compatible to flexible and large area substrates

(viii) thin layer to achieve complete absorption

Published By:

Blue Eyes Intelligence Engineerin and Sciences Publication

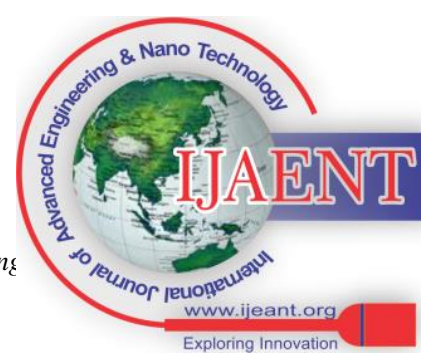


In 2014, according to a research group at MIT and a thesis published by Chuang, an air-stable, room temperature, solution processed $\mathrm{ZnO} / \mathrm{PbS}$ solar cell was demonstrated which reached a certified efficiency of $8.55 \%$, which broke previous record efficiencies of QD solar cells. Photoelectronic spectroscopy confirmed that this improvement was due to the relative band alignment between QD layers. Apart from enhanced efficiency, these cells demonstrate excellent longterm stability in air for more than 150 days without encapsulation. The quantum dots in this architecture serves complimentary functions of light absorption and electron blockage/hole extraction. An important factor was the choice of ligands- Iodide-passivated QDs were found to be stable in air, while organic ligand passivated QDs were found to be prone to oxidation. Another important factor was the removing the commonly used $\mathrm{MoO} 3$ interfacial layer, which gradually develops an unfavourable band alignment in the device with air exposure time.

Around 2016, the first colloidal QD solar cell was built by a research team at the University of Toronto led by Edward $\mathrm{H}$ Sargent of University of Toronto with power conversion efficiency of almost $11.3 \%$.

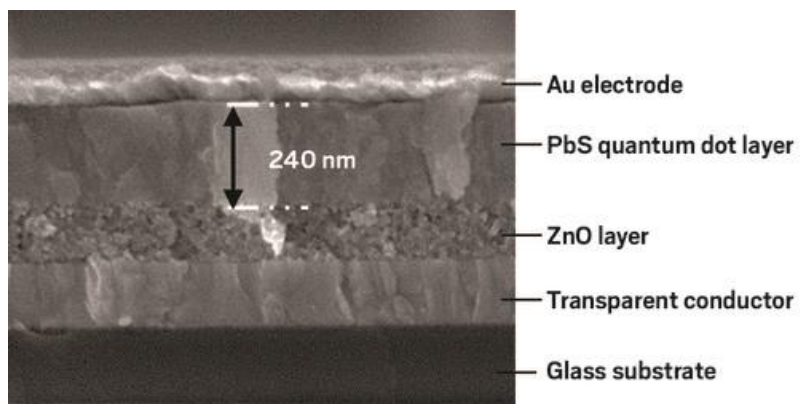

Fig 3: SEM image shows how record setting quantum dot solar cells are built [87]

In 2017, a colloidal QD solar cell was created by the scientists at National Renewable Energy Laboratory (NREL) which achieved a record $13.4 \%$ conversion efficiency.

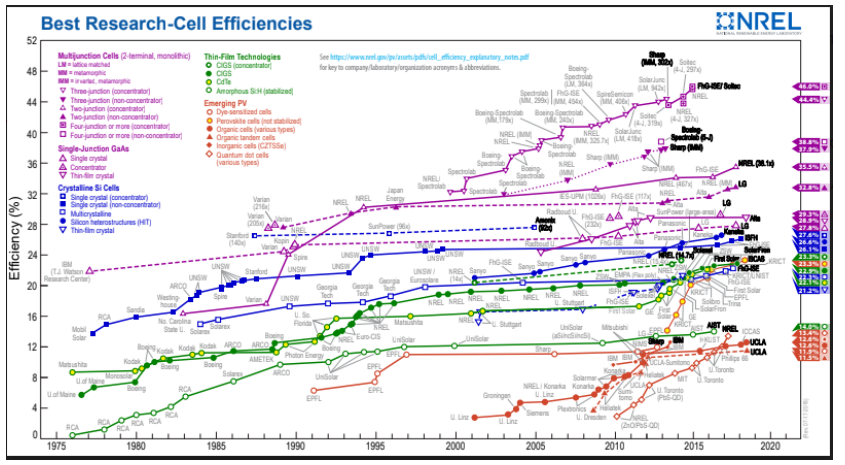

Fig 4: Growth curve of efficiencies of QD solar cells through the years shown in red hollow diamond key as noted by NREL [48]

a. Displays and Solid-state lighting:

The higher chemical stability which enables purer colour emission, lower fabrication costs and compatibility to fexible large substrates make the use of quantum dots more desirable. Multiple colour emission can be achieved using the sizetuneable emission property. The limitations like ageing and low intermixture stability associated with tuneability using multiple compositions are therefore eliminated. Moreover, a high colour rending index (CRI) value is achieved due to the continuous tuneable QD.

\section{b. $\quad$ Light Emitting Diodes (LEDs):}

The salient features required for LED are tuneable and narrow band emission. Both of these are intrinsic properties of QDs basing on their size and composition. Moreover, the printability of QD-LEDs, especially on plastic opens up a host of application for opto-electronic devices which requires flexibility over large areas and likely to be adopted for visual output devices in future.

As per Lutfullin et.al., Figure 5 depicts the outline arrangement of a QD-LED. The outline process proposed by Lutfullin et.al., is as follows [48]:

(i) Spin coating an HTL (hole transporting layer) on ITO (indium tin oxide) and attached to a glass / polymer substrate.

(ii) Deposit QD's by spin-coating. (Perovskite, CdSe or InP based QDs are normally utilized for visible LEDs and PbS QDs are used for infrared LEDs)

(iii) Thereafter the electron transporting layer (ETL) and electrodes are deposited. (Electrodes are of metals like $\mathrm{Ag}, \mathrm{Au}$, and $\mathrm{Al}$ and are deposited using a thermal evaporation system [35-40]

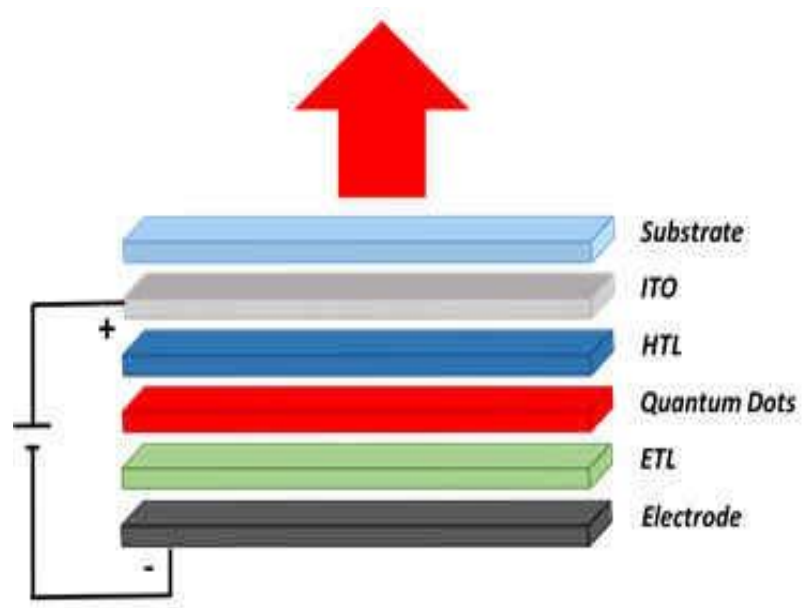

Fig 5: Arrangement of QD LED. Taken from [48]

Some of the salient developments on LED reported by $\mathrm{Hu}$ et.al., is summarised below [106].

(i) QD-LED works on the principle of electroluminescence as against conventional LED which works on photoluminescence.

(ii) QD-LED provides more freedom in device design compared to photoluminescence LED which require a pumping source.

(iii) QD electroluminescence is achieved through the Förster resonance energy transfer (FRET) or direct charge injection methods [106].

(iv) A potential phosphor for white Light Emission is MSQD using CdSe.

(v) In 1994 Alivisatos group produced the first QDLED [108].

Blue Eyes Intelligence Engineerin and Sciences Publication

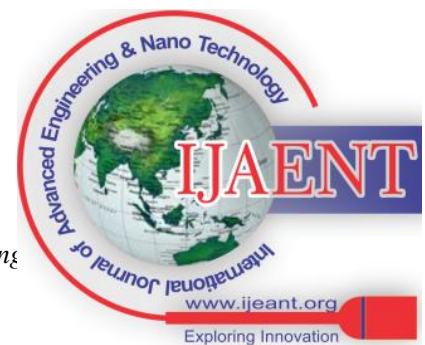




\section{Nanomaterials: Applications in Electronics}

(vi) Klimov et al. reported " $55 \%$ light conversion efficiency, in which a monolayer of CdSe/ZnS quantum dots was put on top of the InGaN quantum well" [33].

(vii) Sun et al., in 2007 reported "QD-LED brightness values of 9064, 3200, 4470 and $3700 \mathrm{~cd} / \mathrm{m}^{2}$ for red, orange, yellow, and green QD-LEDs respectively" [34].

(viii) The smaller QD size and low human optical sensitivity offers a challenge for blue light. Tan et al reported the best QD-LED with CdS/ZnS core/shell and omitted ETL to remove extra organic emission [109].

(ix) White QD-LED not yet commercialised to replace white LED using QD as phosphor.

(x) "Red, green and blue QD-LEDs were successfully fabricated by patterning QDs of different sizes on a layer of zinc oxide nanoparticles in 2012 with brightness of 23,000 $\mathrm{cd} / \mathrm{m}^{\wedge} 2$ and $218,000 \mathrm{~cd} / \mathrm{m}^{\wedge} 2$ for red and green respectively" [88].

(xi) Inorganic QD-LED improves material degradation and electrode contact and offers increased life [110].

\section{d. Phosphors:}

White lights or horticultural lights (Fig 6) can use QDs as phosphors for conversion of blue light to white light with high CRI (colour rendering index) and CCT (correlated colour temperature). A mix of red and green phosphors placed either inside or outside the blue LED package to produce white light are defined as 'on-chip' or 'remotephospor' type respectively. Different blends of phosphors are used for producing various colours of light. For example, red QD phosphors on a blue LED produces a combination of red and blue light which is used in horticulture.

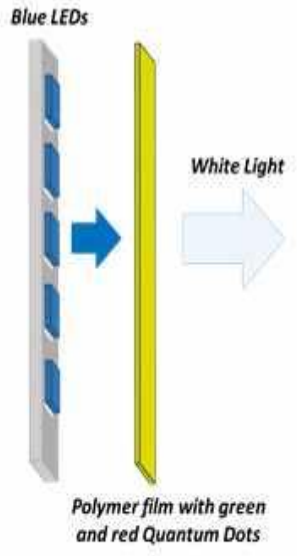

(a)

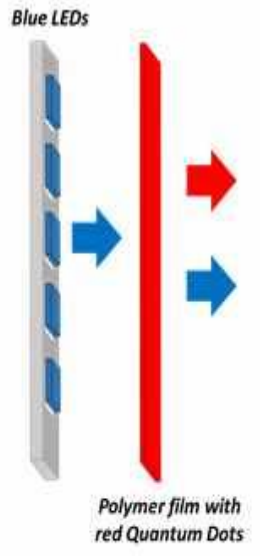

(b)
Fig 6: "Schematics of QD based device for (a) white lighting and (b) horticultural lighting", taken from [48]

e. Liquid crystal display (LCD) backlighting:

The narrow FWHM of light produced using QD is used effectively in the backlighting of the LCD wherein a combination of blue LED and a QD filter with red and green quantum dots is used. The QD filter converts part of the blue light to red and green lights. These lights are thereafter combined to produce a wide range of colour lights on the display. The 'on-chip', 'on-edge' and 'on-surface' are the three types of arrangements used. The 'on-surface' configuration is shown in Fig 7. For usage in LCD backlighting, Perovskite QDs (CdSe-based and InP-based) are very effective. [41-45]

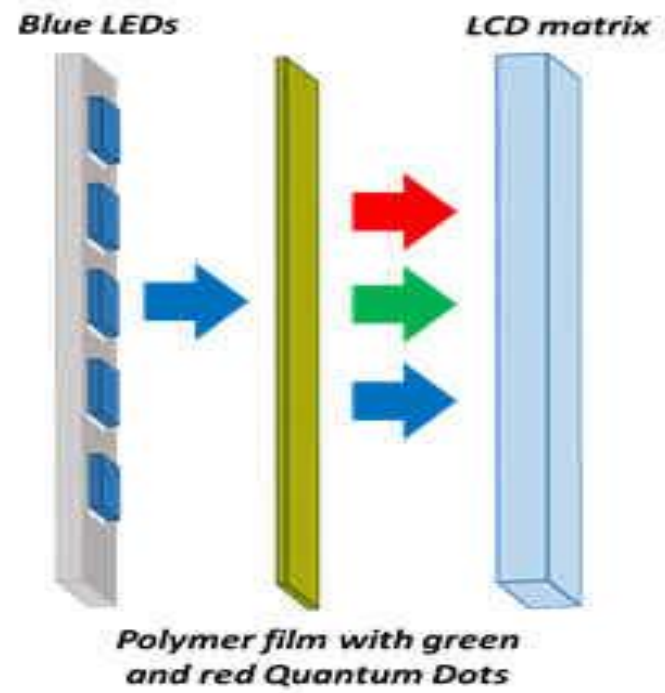

Fig 7: Schematics of Quantum Dots LCD backlighting in the 'on-surface' configuration taken from [48]

\section{f. Photodetectors:}

In view of the simple processes involved in combining QDs with silicon based electronic components and their influence on optical emission/ absorption behaviour based upon the size and type, QDs have found extensive use in photodetectors and image sensors. These applications cover imaging devices including visible light and night vision cameras, gas detection spectroscopy devices, machine vision and other surveillance devices.

Fig 8 shows the structure of a QD based photodetector. A photodetector is fabricated by depositing electrodes on a glass/ ceramic substrate by evaporation. Thereafter, spin coating of colloidal QDs is done on the substrate forming a solid QD film/ composite between electrodes [46-47]. Infrared photodetectors normally use $\mathrm{PbS}$ QDs and UV detectors use perovskites (CdSe and InP based) QDs.

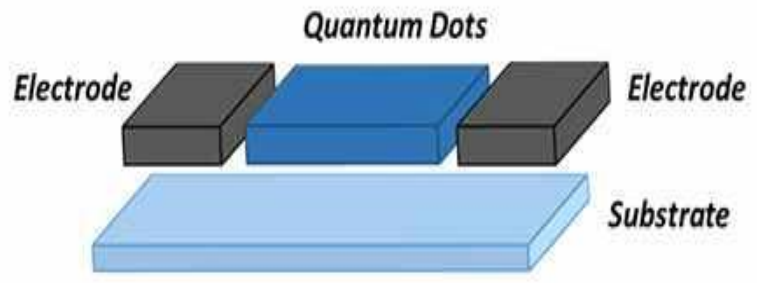

Fig 8. Arrangement of a QD photodetector taken from [48]

\section{DIMENTIONAL}

\subsection{Synthesis Processes:}

\section{Arc Discharge Method}

Though a common method for CNT production, this technique requires the separation of CNTs from soot and catalytic metals.[53]

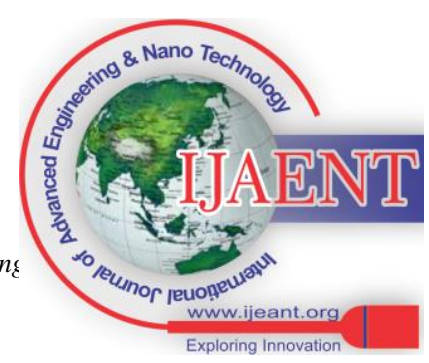




\subsection{Carbon Nanotube}

A type of arc method synthesis called Hipco method is achieved under high pressure and was established at Rice University to produce high quality SWCNTs from the gasphase reaction of iron carbonyl with high pressure carbon dioxide gas. Synthesis using this method creates high quality distribution.

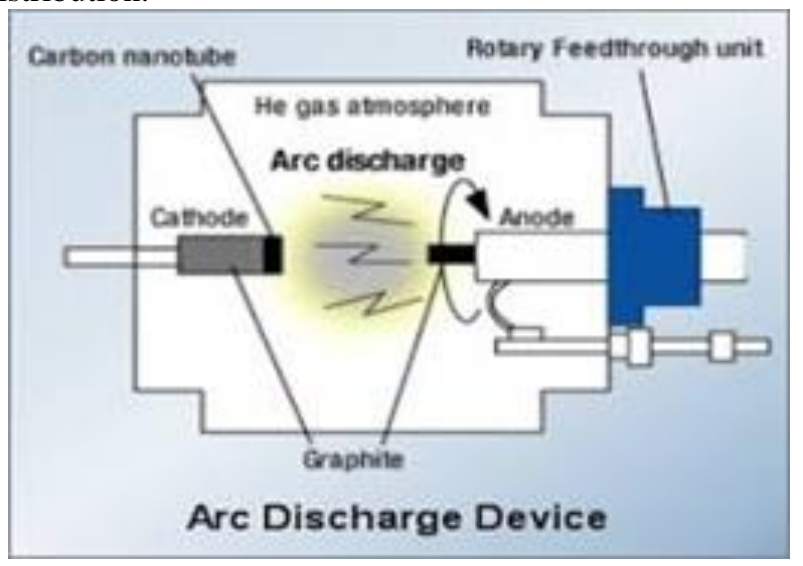

Fig 9: Arc Method for CNT Synthesis[114]

\section{a. $\quad$ Laser methods}

Initially a dual pulsed method was used to synthesize carbon nanotubes with $>70 \%$ purity. The process uses two consecutive laser pulses to reduce the carbon collected as soot and further breaks up the higher sized particles and adds them to the developing nanotube structure. The product looks like a mat of "ropes", whose diameter is about 10 to 20 nanometres and have a length of approximately $100 \mu \mathrm{m}$. in every rope we can find a bundle of SWCNTs which lie parallelly to a common axis. The nanotube diameter and alignment can be changed by varying the different parameters including catalyst configuration and temperature.

\section{b. Chemical Vapor Deposition}

Catalysed chemical vapor deposition of hydrocarbons is commonly used for CNT synthesis. Catalytic Chemical Vapour Deposition of $\mathrm{C} 2 \mathrm{H} 2$ over cobalt \& iron catalysts supported on silica or zeolite produces large amounts of CNTs. The catalyst's cobalt content influences the carbon deposition and $\mathrm{pH}$ affects the CNTs' selectivity.

It can be shown experimentally that the growth of SWNT or bundles of SWNT in ethylene atmosphere can be induced by supported catalysts (eg. Fe, Co,Ni) which contains either a single metal or a mixture of metals. Carbon nanostructures with open ends and no caps have also been prepared by using ethylene with reaction temperatures of $545^{\circ} \mathrm{C}$ for Nickelcatalysed CVD, and $900^{\circ} \mathrm{C}$ for an uncatalysed process. SWCNT and DWCNTs on Mo and Mo-Fe alloy catalyst can also be produced.

Nanotube chips which have isolated SWCNTs at controlled locations have been produced using $\mathrm{CH} 4$ as a carbon source. High yields of SWCNTs can be formed by catalytically decompositing a mixture hydrogen and methane over well dispersed metal particles (Co,Ni,Fe) on $\mathrm{MgO}$ at $1000^{\circ} \mathrm{C}$. In this process the $\mathrm{CH} 4$ environment which decomposes at high temperature stops further growth of the nanotubes resulting in a higher ratio of SWCNT. materials in small quantities and not feasible for commercial

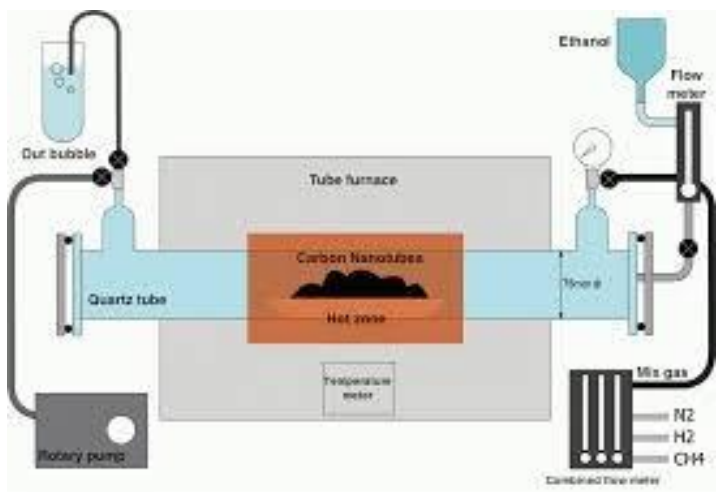

Fig 10: Catalyzed CVD for CNT Synthesis [114]

Plasma arcing of carbonaceous materials, specifically graphite can be used to create CNTs and fullerenes.

The other methods of producing CNTs are diffusion flame synthesis, electrolysis, polymer heat treatment and lowtemperature solid pyrolysis.

\subsection{Applications of CNTs}

The SWCNT presents excellent structural and conductive material properties. Each atom donates a delocalized pi electron which is not bound by the donor atom and has the freedom to oscillate throughout the structure. This resulted in "the first known molecule with metallic-type electrical conductivity". The high-frequency C-C bond vibrations in carbon nanotubes provides intrinsic thermal conductivity which is even higher than diamond. Thus, extraordinary electrical and heat conductivity and mechanical properties can be seen. They are excellent electron field-emitters. Keeping all these properties in mind plus the fact that CNTs are carbon polymers offer opportunities for further modifications of structure and optimization of dispersion as well as solubility. CNT's can be called "molecularly perfect, which means that they are normally free of property-degrading flaws in the nanotube structure".

\section{a. $\quad$ CNT Field Effect Transistor}

Scaling the silicon MOSFET as per Dennard scaling was to shrink the MOSFET, reduce the voltage and maintain a constant E-field which would result in increased current density, lower power and faster switching. [56] The Dennard transistor scaling prediction [89] is depicted in Fig 11.

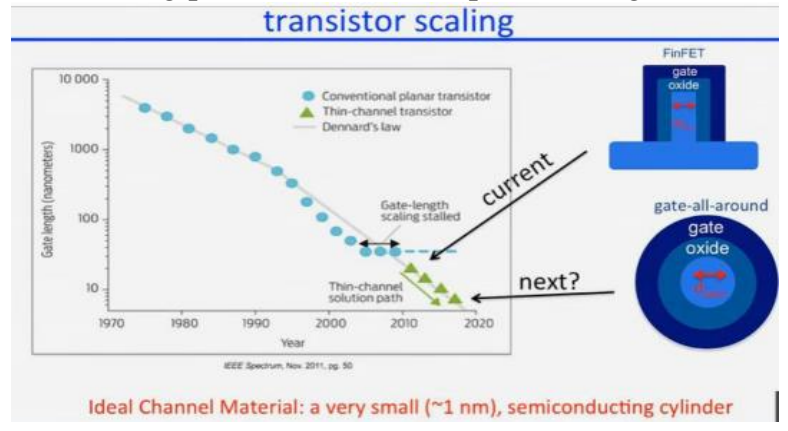

Fig 11: Transistor scaling [89]

It was apparent that this level of channel scaling in MOSFET was inhibitive.

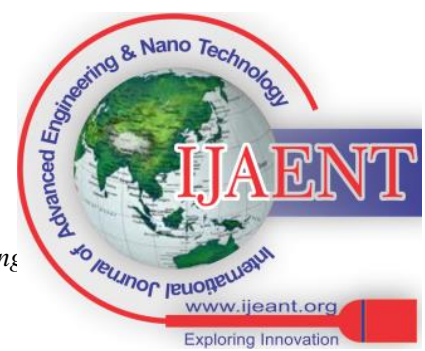




\section{Nanomaterials: Applications in Electronics}

On the other hand CNTFET with a typical arrangement as shown in Fig 12 showed no degradation down to channel lengths of $9 \mathrm{~nm}$ and transistor performance in terms of current density was 3 times higher than silicon as reported by Franklin et al (Fig 13a). As brought out by Tulevski et al in 2014 the CNT based FET performance is three times higher while the power input is three times lower as compared to FinFET as shown in Fig 13b. Kim et al., has reported that in case of MOSFETs and CNTFETs of same channel length, Power Delay Product (PDP) of MOSFET based logic gates is 90 to 100 times greater than the PDP of CNTFET based logic gates.[93][94].

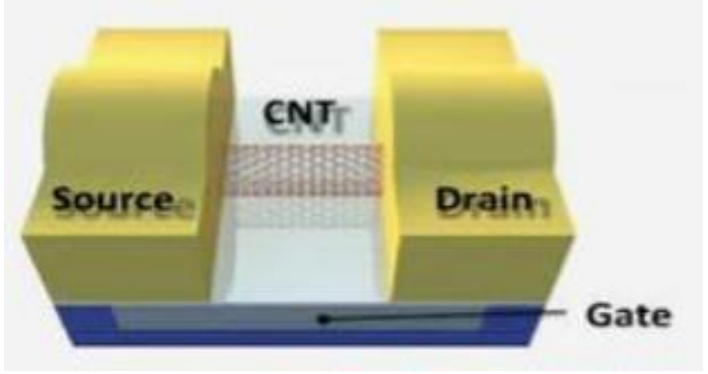

Fig 12: CNTFET[111]

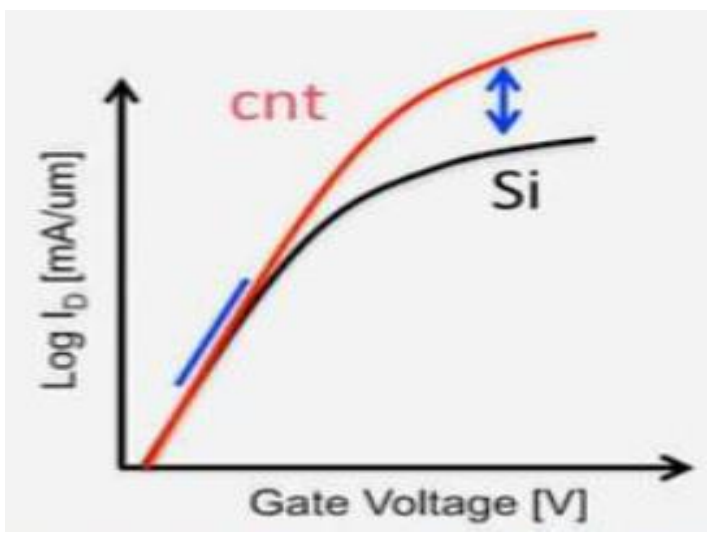

Fig 13a: Current Density comparison

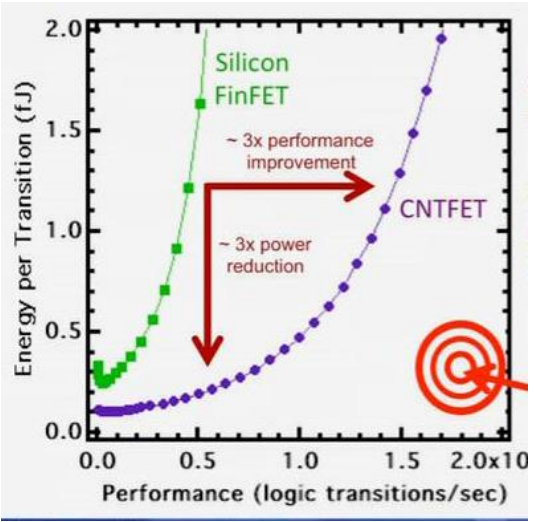

Fig 13b: Performance \& Power Comparison

Hence the CNT-FETs were proposed as the future choice which uses the semiconductor CNTs as the channel. The physical structure of CNTFETs is very similar to that of MOSFETs. CNTFET have high drive current, large transconductance, high temperature resilience, strong covalent bond. It can also reduce the scattering probability due to the $1 \mathrm{D}$ confinement so that the device may operate in ballistic regime has brought out by Franklin et al in 2012. On the basis of geometry, CNTFETs can be classified as:

(i) Bottom Gate CNTFET:

Bottom gate CNTFETs require very high gate voltages to be turned on. Apart from this, they exhibit low transconductance, high on-state resistance of several MQ, and no current saturation

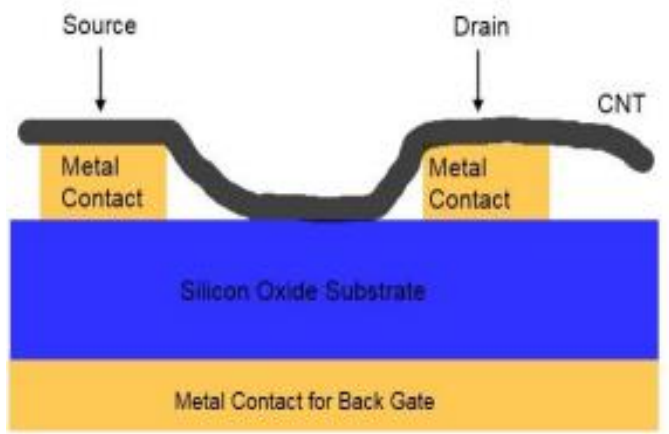

Fig 14: Bottom Gate CNTFET - side view of carbon nanotubes deposited on a silicon oxide substrate [111]

(ii) Top Gate CNTFET:

Top gate CNTFETs improves the device performance. A better turnout is obtained by this structure due to the adoption of better device geometry and scaling of dimension [111]

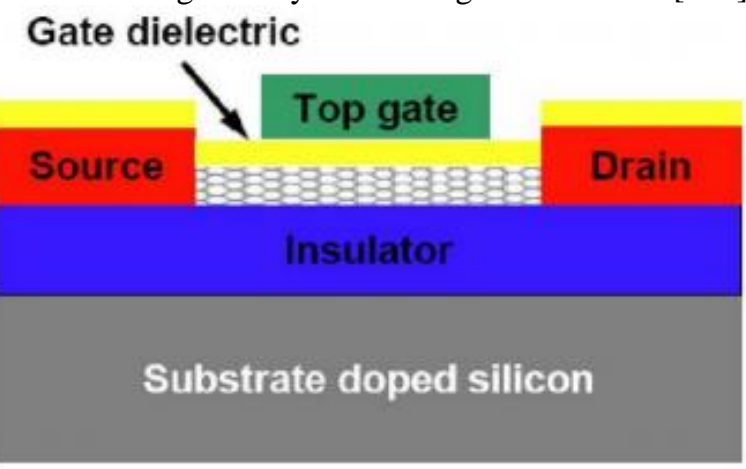

Fig 15: Structure of Top Gate CNTFET [111] (iii)Coaxial gate CNTFET

Coaxial gate CNTFET is also known as gate all-around CNTFETs. It improves the electrical performance of the CNTFET, improving the device on/off ratio and reduces the leakage current.

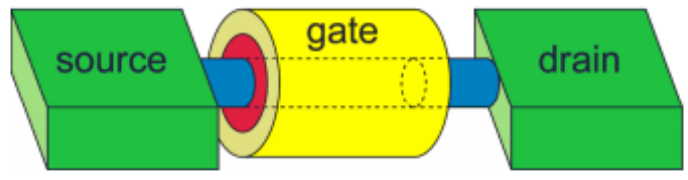

Fig 16: Structure of coaxial gate CNTFET [111]

On the basis of operation, CNTFETs can be classified as follows:

Published By:

Blue Eyes Intelligence Engineerin and Sciences Publication

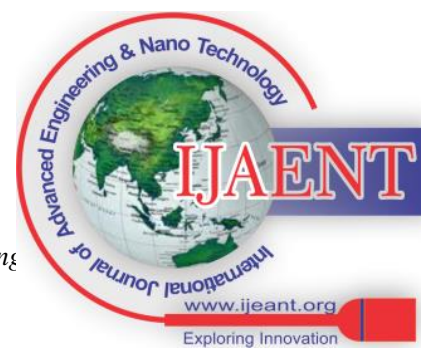




\section{(i) Schottky barrier CNTFET:}

The working of SB-CNTFET can be explained by the principle of direct tunnelling through the Schottky barrier at the source channel junction. The gate voltage controls the barrier width and hence the transconductance. There is limiting of the channel current due to the large barrier present as a result of low gate bias. The barrier width reduces with increase in the gate bias which further increases the quantum mechanical tunnelling through the barrier and eventually the current flow in the transistor channel. The modulation of the transmission coefficient is responsible for the transistor action.

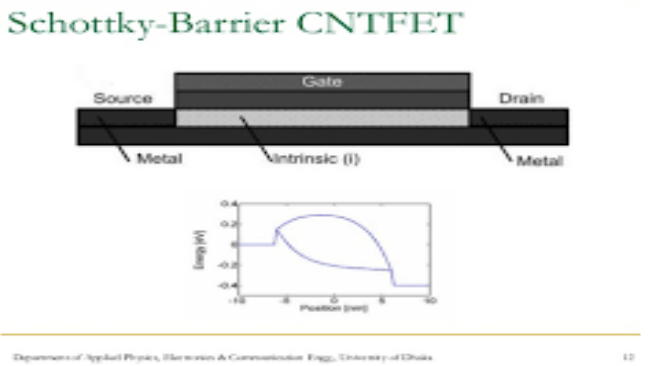

Fig 17: Schottky barrier CNTFET [111]

\section{(ii) MOSFET like CNTFET:}

These structures use heavily doped terminals as against the metal terminals in Schottky barrier CNTFET. It overcomes problems faced by SB-CNTFETs by operating like normal barrier height by gate voltage application. The drain current is controlled by the charge induced in the channel by gate

Although carbon nanotube (CNT) is accepted as the best replacement for silicon in field-effect transistors. [51,54], the evolution of the industrial production process holds the key. Despite IBM researcher's ability to create a logic circuit with 10,000 CNTFETs on a single chip based on "high density integration of carbon nanotubes via chemical self-assembly" [50,51,52,96,97,101] and the Stanford engineers' making of the first nanotube computer which is equivalent to Intel 4004, the replacement of silicon with CNT around 2020 holds a major challenge. As per the semiconductor industry roadmap, by 2020 "transistors must have features as small as $5 \mathrm{~nm}$ to keep up with the continuous miniaturization of computer chips. The current best is $14 \mathrm{~nm}$ ".

The challenges facing CNT is the difficulty in obtaining the high purity of semiconductor CNTs and placing them correctly. The CNT available commercially contain about 33$60 \%$ metallic CNTs which are prone to initiating failures in FET by short circuiting. In the past, manufacturers achieved 88-94\% precision which is much below the estimated $99.96 \%$ specified by ITRS for commercial manufacturing. Arrays of CNTs with very high purity have to be built which is a challenge faced by the industries. Chen et al., and Cui et al., proposed plasma treatment to convert metallic CNT to semiconductor type and $\mathrm{Na}$ et al., proposed protein-coated nanoparticles in the contact areas to convert metallic CNT to semiconductor type to address the purity aspect. With regard to building arrays of high purity CNT the engineers of Wisconcin University have reported a technique called floating evaporative self-assembly. MOSFETs. It works "on the principle of modulation of the terminal".[95].

Claims of achieving purity rates of $99.98 \%$ have been made by the Wisconsin team. The "schematic illustration of the iterative process used to fabricate aligned nanotubesSWCNT" driven by the spreading and evaporation of controlled doses of organic solvent at the air water interface is given in the figure below:
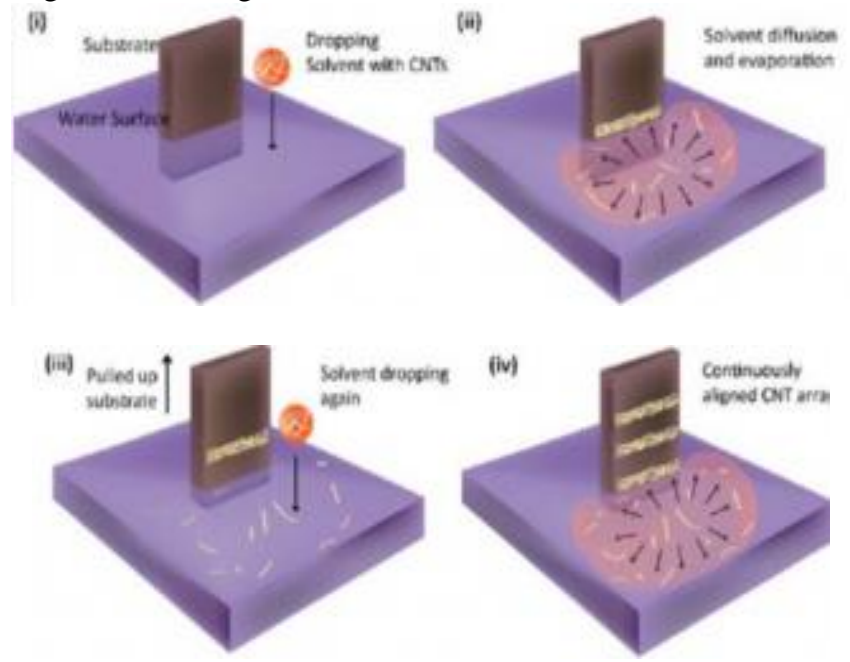

Fig 18: Fabrication of aligned nanotubes [112]

CNTs are outstanding materials for super capacitor electrodes. The incredibly high electrical conductivity and sharpness of the tip of CNTs are responsible for the claim that these are the best-known field emitters of any material. As we reduce the tip's radius of curvature, the concentration of the electric field increases which further increases the field emission. The sharpness of the tip also means that the emission occurs at low voltages which is an important feature used in the construction of low-power electrical devices. CNTs also have the ability to carry a significant amount of high current density". Towards this, CNTs have a variety of applications which include field emission flat panel displays using separate nanotube electron gun for each individual pixel in the display as against the older CRT display with single electron guns. Using these characteristics, CNTs have other applications as well, such as- general types of low-voltage cold-cathode lighting sources, lightning arrestors, and electron microscope sources.

\subsection{Carbon Nanofibre}

\subsubsection{Synthesis Processes:}

There are a number of techniques used to fabricate nanofibers, some of them are mentioned

\section{a. Drawing:}

Drawing is the technique to fabricate long single nanofiber one-by-one from the droplet of polymer. The diameter of the resultant nanofiber depends on the type of the polymer, its composition, drawing velocity and speed of evaporation of the solvent. Only a strong viscoelastic material that can undergo strong deformation during this process when stress is applied while pulling the nanofibere, can be used in this process. This is a major practical disadvantage. Thus, choice of material is limited in this process.

Blue Eyes Intelligence Engineerin and Sciences Publication

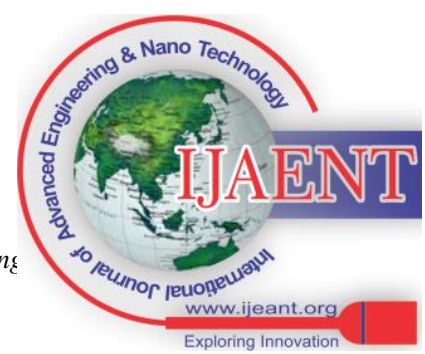




\section{Nanomaterials: Applications in Electronics}

\section{b. $\quad$ Template Synthesis:}

A metal oxide membrane having pores of nanoscale diameter is used in this process. The metal oxide membrane is placed over a solidifying solution. Polymer solution is extruded by the membrane by applying high water pressure over it. The polymer solution after passing through the membrane comes in contact with solidifying solution which converts the polymer solution into nanofibers. The diameter of the nanofibers depends on the diameter of the pores of membrane.

\section{c. Phase Separation:}

In this mechanism, separation of phases is involved due to the physical incompatibility. A polymer is mixed with a suitable solvent, gelation occurs in this mixture and the final step involves the separation of phases. One of the phases-which is that of the solvent- is extracted leaving behind the other remaining phase. The remaining phase is the nanofibrous structure.

\section{d. Self-Assembly:}

Self-assembly processing involves the smaller molecules as basic building blocks to build-up the nanofibers. Molecules are spontaneously organized into an individual and stable structure with pre-programmed noncovalent bonds. Nanofibers of very thin diameter can be fabricated using this process, but it requires very complicated procedures. The low productivity is another limitation of this method.

\section{e. Electrospinning:}

Electrospinning involves the application of high voltage on melts or solutions which results in the formation of a pendant droplet. The pendant droplet deforms into a conical droplet or taylor droplet at the tip of the needle when the surface tension of the fluid is overcome by the increasing electrostatic repulsion. With further increase in voltage when the surface tension of the taylor droplet is overcome, a "fine charged jet of polymer solution is ejected from the needle tip". [113] This interaction between the electric field and the surface tension of the fluid leads to stretching of the jet stream making it undergo a whipping motion leading to the evaporation of the solvent. The jet stream transforms into a long thin filament which eventually solidifies and deposits on a grounded collector and forms a uniform fibre. This process produces fibres with a range of diameters from $\mathrm{nm}$ to $\mu \mathrm{m}$ scale. Electrospinning is regarded as a versatile and simple method to generate ultrafine fibres that are between tens of nanometers and several micrometers in diameter using materials such as inorganic materials, polymers, composites etc. Electrospinning is a continuous process that results in the formation of longer fibres compared to fibres prepared by other chemical or physical methods [57]. Tuneable morphologies and structures can produce desired properties by controlling the process parameters and/or designing special electrospinning apparatus. A unique advantage of electrospinning is that complex hierarchical structures can be obtained via controlled calcinations which is not easy using conventional methods. [58].

There are some disadvantages of this method. Firstly, in the electrospinning is limited and the structure and performance of NFs are not well researched. Secondly, the performance and range of application of electrospun inorganic NFs have preparation of organic NFs, the variety of polymers used in

been limited due to their friability after calcination, although inorganic NFs have a potential application in many fields such as energy devices, high temperature filtration, biological tissue engineering, and efficient catalysis. Thirdly, electrospinning has been implemented at industrial level; however, in terms of producing fibres for the application of filters electrospinning is inferior to traditional methods due to its higher cost to produce fibres with large diameter. Furthermore, it remains a challenge to fabricate NFs with diameters less than $10 \mathrm{~nm}$ by electrospinning [59].

\subsection{Applications}

\section{a. Dye sensitized Solar cells:}

Dye-sensitized solar cells (DSSCs) can directly convert light into electricity with the help of a photosensitizing dye. A DSSC has three primary components: a photoanode, a counter electrode, and an electrolyte.

The composition of photoanode is a coating of porous semiconductor film on a transparent conducting glass where the photosensitizing dye is adsorbed on this porous film. In DSSCs, once the photosensitizer absorbs photons, the photoelectrons first move into the conducting band of the semiconductor from the photosensitizer and are collected on the photoanode. The photoelectrons further transfer to the counter electrode through the external circuit to form current. In this process, the maximum light absorption and efficient charge transport affect the overall photoelectric conversion efficiency. Hence, the photoanode plays a vital role. Electrospun metal oxide nanofibers as a thin film coated with photoanode has been thoroughly researched due to their high specific surface area and 1D fibrous morphology. The high specific surface area enhances the absorption of photosensitizing dye and the 1D fibrous morphology results in a better charge conduction capability and reduced chargecarrier recombination [60,61]. In addition, the large and controllable pore sizes of electrospun NFs contribute to the penetration of viscous polymer gel electrolyte [62]. $\mathrm{TiO}_{2}$ anatase NFs prepared by electrospinning have been mainly used as photoanode material $[63,64,65]$; however, one of the major problems is their poor adhesion to conductive substrate. Many effective methods have been adopted to solve the problem, such as converting electrospun nanofibers into nanorods [66], using hot press pre-treatment [67], and introducing ultrathin surface treatment layer (STL) [68].

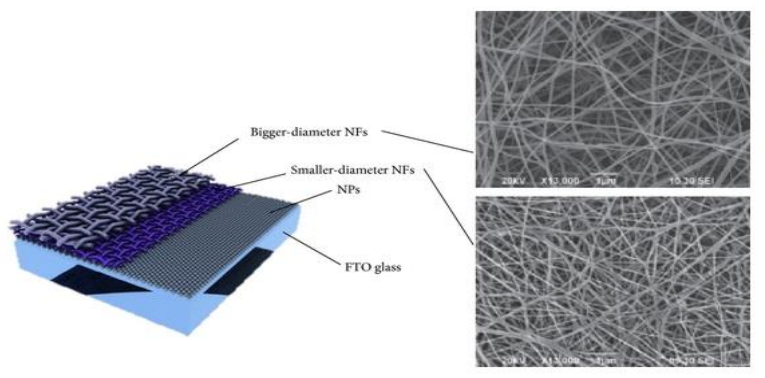

Fig 19: SEM images of the bilayer TiO2 nanofibers photoanode of a dye-sensitized solar cell (adapted from [74]) and Sciences Publication

(C) Copyright: All rights reserved.

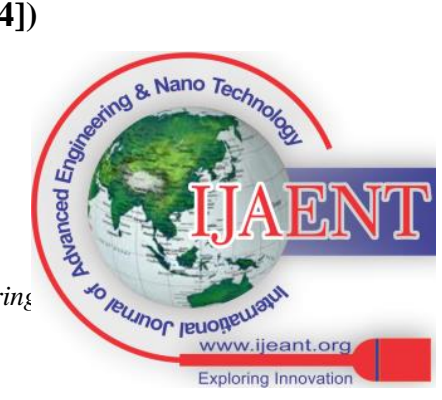




\section{DIMENTIONAL}

\section{a. Graphene}

Graphene consists of single-atom thick sheets of sp2 bonded carbon atoms arranged in a 2D honeycomb lattice. "Because of this structure, graphene is characterized by a number of unique and exceptional structural, optical, and electronic properties". [69,90] It has increased strength due to its covalent C-C bonds which can be used in mechanical applications. It can improve the thermal conductivity of materials resulting in more efficient heat dissipation of electronic components. The impervious property of graphene to both gases and liquids makes it an appropriate material to be exploited for a wide range of barrier applications. It is highly suitable to be used in energy storage applications due to its exceptional ability to store electrical energy at very high densities.

\subsubsection{Synthesis processes:}

A number of methods can be used to produce graphene sheets; however, the three primary methods are Mechanical Exfoliation, Chemical Vapor Deposition (CVD) onto metal or Si substrates, and Chemical, Electrochemical, or Thermal Reduction of GO.

\section{a. Chemical vapour deposition:}

This method is the most preferred for producing graphene in bulk as it can be used to "fabricate large areas of graphene while limiting the number of defects" [70]. Graphene obtained by using this method can have a carrier mobility that reaches values as high as $\sim 2000-4000 \mathrm{~cm} 2 \mathrm{~V}-1 \mathrm{~s}-1$ $[71,72,77]$.

\section{b. Mechanical exfoliation:}

"Mechanical exfoliation using the Scotch tape method or by rubbing lithographically patterned pillars with "tipless" atomic force microscopy (AFM) cantilevers can be used to generate very high-quality graphene with a carrier mobility that reaches $\sim 10 \quad 000 \quad \mathrm{~cm} 2 \quad \mathrm{~V}-1 \quad \mathrm{~s} \quad-1$ at room temperature".[71]. "By this method, the physical limit of the graphene sheets that are produced has lateral dimensions on the order of tens to hundreds of micrometers. However, mechanical exfoliation has poor reproducibility and is not amenable to large-scale fabrication". [102].

\section{c. $\quad$ Thermal reduction of GO:}

The production of graphene sheets using the method of thermal reduction of GO has been proven to be economical for the production of small graphene sheets but the electrical conductivity of the rGO sheets is lower than those produced by the CVD and mechanical exfoliation processes [73]. Both the the quality of graphene and quantity required are essential for the choice of production process as shown in the figure 23.

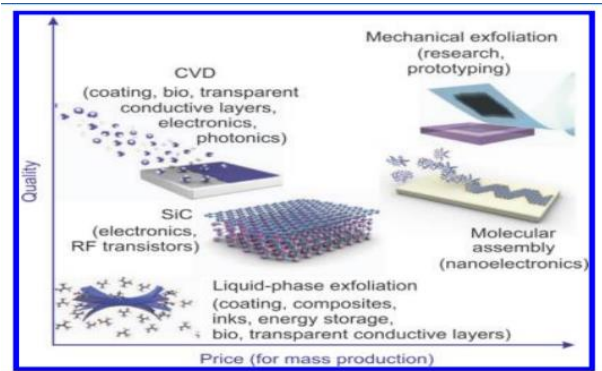

Fig 20: Methods for the mass-production of graphene [74]

\subsubsection{Applications:}

a. Biosensors and chemical sensors

Graphene when used in the structural architecture of devices exhibits low electrical noise. These electrical properties can be enhanced by the absorption of the analyte on its surface which in turn improves the sensitivity levels of the sensors. $[75,76]$

\section{b. $\quad$ Graphene Transistors (GFET)}

FETs using graphene as an active channel layer has shown excellent electrical and mechanical characteristics. Since most semiconductor transistor devices are 3-dimensional, surface electric charges do not always penetrate deep into the device which significantly reduces the device sensitivity. [77] Against this, graphene-based FETs are one carbon thick and thus do directly exposes the channel to any molecule present in its environment. The scientists from the Manchester Centre for Mesoscience and Nanotechnology further proved that " $\mu$ m-sized sensors fabricated from graphene were capable of detecting individual gas molecules attached or detached from the surface." "Graphene based FETs have a higher carrier mobility which often reach levels greater than $100,000 \mathrm{~cm}^{2} \mathrm{~V}^{-}$ ${ }^{1} \mathrm{~s}^{-1}$ for hBN-encapsulated single-crystal CVD graphene. These devices also have a residual charge carrier density of the order of $5 \times 10^{11} \mathrm{~cm}^{-2}$ " [90]. The extrinsic scattering that occurs due to charged impurities at the interface of graphene/dielectric result in degradation of the mobility of charge carriers as reported by Chen et al. [100] Lowering the density and effect of charged impurities is critical to improve the mobility. Hence, dielectric material for both substrate and top gate are replaced with high-k materials which reduces the charged impurity scattering because of increased screening effect. Graphene's natural state does not have a band gap \& cannot completely block current in the transistor's off-state. Band gap is induced by limiting one dimension and making nanoribbons leading to a larger on-off ratio as reported by Han et al and $\mathrm{Li}$ et al. $[98,99]$. As per the experimental results demonstrated by Lee et al., "in a high performance, graphene based thin film transistor (TFT) on a plastic substrate with graphene active layer, electrode, and ion gel gate dielectrics, this single layer graphene FET provided hole mobility of $26 \mathrm{~cm}^{\wedge} 2 / \mathrm{V}$. s and electron mobility of $20 \mathrm{~cm}^{\wedge} 2 / \mathrm{V}$. s at $-0.1 \mathrm{~V}$ of drain bias. " But this device showed lower carrier mobility than other graphene-based FETs due to moisture and other chemical species from the porous structure of the PDMS accumulated in the graphene channel. This structure was experimented upon solely due its flexibility and stretchability.

\section{c. Photovoltaic devices}

In photovoltaic devices, graphene sheets have been mostly used as charge acceptors [78], transparent electrodes [79, 80], and charge transport bridges, for example, using graphene as a novel charge acceptor, Guo et al. [81] developed quantum dots solar cells with the multilayered graphene-quantum dots device structure and energy level alignment. The resulting device exhibited an incident power conversion efficiency $16 \%$ and a photoresponse $10.8 \mathrm{~A} / \mathrm{m} 2$ under $1000 \mathrm{~W} / \mathrm{m} 2$ illumination, a milestone in high performance QDSC development.

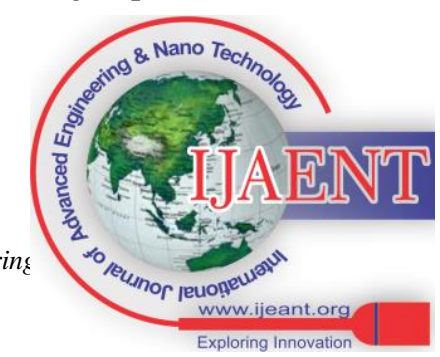




\section{Nanomaterials: Applications in Electronics}

$d$. DSSC (Dye sensitized Solar Cell)

Yang et al., [82] reported graphene fabricated as 2D bridges in the electrodes of DSSCs. These bridges lead to a "fast electron transport, low recombination rate, and a high light scattering". When compared with the nanocrystalline titanium dioxide photoanode, it was found to have shown a total conversion efficiency of $6.97 \%$, an increase of $39 \%$. These were also found to be much better than the $1 \mathrm{D}$ nanomaterial composite electrode.

As per Kim et al., Graphene/ TiO2 can be used in both DSSC and quantum dots solar cells (QDSC). In the future, due to their high photon-electron efficiency \& cost effectiveness, DSSC could be the alternative to traditional silicon solar cells. [83][84]. Tang et al [85] has reported " $\mathrm{rGO} / \mathrm{TiO} 2$ indiun tin oxides as photoanode for DSSC". The increase of electron transport results in an increase of the short-circuit current density which eventually results in a fivefold increase in power conversion as when compared to pure $\mathrm{TiO} 2$.

\section{e. $\quad$ Optoelectronic devices}

An ideal material for usage in optoelectronic applications must be able to transmit more than $90 \%$ of light and also offer electrically conductive properties exceeding $1 \times 10^{\wedge} 6 \Omega \mathrm{m}$. Graphene is almost transparent and optically transmits upto $97.7 \%$ of light. Its highly conductive, tensile and flexible nature makes it a great suitable material for the future of optoelectronics.

\section{f. Supercapacitors}

Graphene based supercapacitor materials have significant industrial application as reported by Wang et al [86]. A list of such materials is shown at Fig 24.

\begin{tabular}{|c|c|c|}
\hline Material & $\begin{array}{l}\text { Specific } \\
\text { Capacitance } \\
(\mathrm{F} / \mathrm{g})\end{array}$ & $\begin{array}{l}\text { Energy } \\
\text { density } \\
\text { Power } \\
\text { density }\end{array}$ \\
\hline Chemically reduced CO & $\begin{array}{l}135 \\
99\end{array}$ & \\
\hline $\begin{array}{l}\text { Graphene-hydrous } \mathrm{RuO}_{2} \\
\text { (38.3 wts) }\end{array}$ & 570 & $\begin{array}{l}20.1 \mathrm{Wh} / \mathrm{kg} \\
\text { at } 100 \mathrm{~mA} / \mathrm{g} \\
10 \mathrm{~kW} / \mathrm{kg} \text { at } \\
4.3 \mathrm{~W} \mathrm{~h} / \mathrm{kg}\end{array}$ \\
\hline Graphene $\left(2675 \mathrm{~m}^{2} / \mathrm{g}\right)$ & s5o & \\
\hline $\begin{array}{l}\text { Graphene (microwave assisted } \\
\text { reduction of } \mathrm{CO} \text { ) }\end{array}$ & 191 & $\begin{array}{l}\text { At } 150 \mathrm{~mA} / \\
\mathrm{g} \text { discharge } \\
\text { current }\end{array}$ \\
\hline $\begin{array}{l}\text { Thermal reduction in propylene } \\
\text { carbonate }\end{array}$ & 120 & \\
\hline Graphene (hydrazine reduced GO) & 205 & $\begin{array}{l}28 \mathrm{Wh} / \mathrm{kg} \\
10 \mathrm{~kW} \mathrm{~h} / \mathrm{g}\end{array}$ \\
\hline $\begin{array}{l}\text { Graphene-PANI (50:50 wt2) } \\
\text { (microwave-solvothermal) }\end{array}$ & 408 & \\
\hline $\begin{array}{l}\text { Graphene-PANI (in situ anodic } \\
\text { electro-polymerization of PANI } \\
\text { film on graphene paper) }\end{array}$ & 233 & \\
\hline Graphene-PAN & (1046) & \\
\hline Graphene-MnO & 216 & \\
\hline $\begin{array}{l}\text { Polymer modified graphene } \\
\text { sheet + MWCNT }\end{array}$ & 120 & \\
\hline Curved Graphene Sheets & $\begin{array}{l}100-250 \text { at } \\
\text { current } \\
\text { density } 1 \mathrm{~A} / \mathrm{g}\end{array}$ & $\begin{array}{l}85.6 \mathrm{Wh} / \mathrm{kg} \\
\text { at } 1 \mathrm{~A} / \mathrm{g}\end{array}$ \\
\hline Thermally reduced graphene & $75 \mathrm{~F} / \mathrm{g}$ & $31.9 \mathrm{Wh} / \mathrm{kg}$ \\
\hline & $117 \mathrm{~F} / \mathrm{g}$ & - \\
\hline $\mathrm{MnO}_{2}$ nanowire-graphene & $31 \mathrm{~F} / \mathrm{g}$ & $30.4 \mathrm{Wh} / \mathrm{kg}$ \\
\hline
\end{tabular}

Fig 21: Graphene based supercapacitor materials [86]

\section{V.DIMENTIONAL}

Bulk nanomaterials or 3D nanomaterials are materials that are not confined to the nanoscale in any dimension. They are characterized by having dimensions above 100nm. These materials possess a non-crystalline structure. 3D nanomaterials can contain dispersion of nanoparticles, bundles of nanowires and nanotubes as well as multinanolayers. In these, all dimensions are in macroscale.

\section{VI.CONCLUSION}

Even though photovoltaic devices have a very high theoretical energy conversion limit i.e above 33\% for single junctions and ultimately close to $90 \%$ if suitable materials are found, practically only about a maximum of $13.4 \%$ efficiency has been reported till date. Life cycle constraints (toxicity, recyclability, etc) are a major issue and will become more prevalent as the productions reach volumes near the terawatt scale. Increasing number of researchers are engaged towards addressing this issue. One of the significant advantages of QDs in solar cells is their capability of capturing the untapped energy of UV and IR wavelengths of the solar radiation as well and extensive research is ongoing to increase the practical efficiency limits and to be able to maximise the absorption of energy in these spectra. The carbon nanotube transistor certainly offers the possibility of replacing the silicon transistor in future. [49]. Researchers have already established that it would meet the low power and high current density performance parameters and also the scaling demands as per Moore's law and Dennard's transistor scaling for use in future Digital Logic Circuits and memory chips (SRAMs).[55]. However, the current challenge is the industrial production of the chips with CNTFET with channel lengths of less than $10 \mathrm{~nm}$ without losing out on the channel array precision and purity levels. The continued efforts of IBM have resulted in a chipset with 10,000 nanotube transistors but this has to reach a billion transistors to make it viable. The breakthrough in the fabrication process as reported by the engineers at Wisconsin University and works of other researchers holds the key. All this needs to be achieved as per the targeted time frame for industrial production around 2020 to meet the scalability challenge facing the silicon chips. The GFETs is poised slightly behind the CNTFET in terms of the timelines for their industrial production. While Graphene does not have the constraint of dimensional / orientation impact as in the case of CNT it surely shares similar challenges in terms of purity of the Graphene material for use as FET channel. Graphene application as 2D bridges in Dye Sensitised Solar Cells and as sensors for gas molecule detection holds significant industrial application in future. The paper has endeavoured to highlight the facets of research on nanomaterials and its influence on the electronic components and devices in the future and hence will redeem itself as the 'toolkit for future electronics'.

\section{REFERENCES}

1. Arellano IHJ, et al. 3-component low temperature solvothermal synthesis of colloidal cadmium sulfide quantum dots. Mater Lett. 2010;64(6):785-788. doi: 10.1016/j.matlet.2010.01.021. [Cross $\underline{\text { Ref] }}$

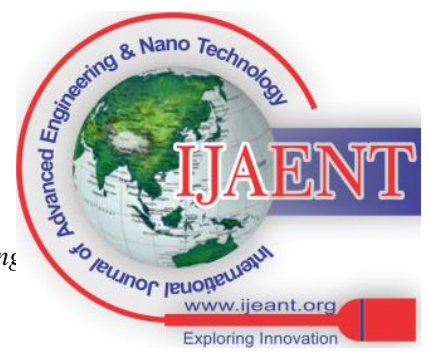


2. Kalasad MN, Rabinal AK, Mulimani BG. Ambient synthesis and characterization of high-quality CdSe quantum dots by an aqueous route. Langmuir 2009; 25(21):12729-12735 doi: 10.1021/la901798y [PubMed] [Cross Ref]

3. Guo J, Yang W, Wang C. Systematic study of the photoluminescence dependence of thiol-capped CdTe nanocrystals on the reaction conditions. J Phys Chem $\quad$ B. 2005;109(37):17467-17473 doi:10.1021/jp044770z [PubMed] [Cross Ref]

4. Zhou L, et al. One-pot large-scale synthesis of robust ultrafine silicahybridized CdTe quantum dots. ACS Appl Mater Interfaces. 2010;2(4):1211-1219.

10.1021/am9009296. [PubMed] [Cross Ref]

5. Law WC, et al. Aqueous-phase synthesis of highly luminescent CdTe/ZnTe Core/Shell quantum dots optimized for targeted bioimaging Small 2009; 5(11):1302-1310 doi:10.1002/smll.200801555. [PubMed][Cross Ref]

6. Zeng QH, et al. Synthesis and optical properties of type II CdTe/CdS core/shell quantum dots in aqueous solution via successive ion layer adsorption and reaction. J Phys Chem C. 2008;112(23):8587-8593. doi: 10.1021/jp711395f. [Cross Ref]

7. Xia YS, Zhu CQ. Aqueous synthesis of type-II core/shell CdTe/CdSe copper(II) Analyst 2008; 133(7):928-932 doi:10.1039/b801963k. [PubMed][Cross Ref]

8. Li H, Shih WY, Shih WH. Non-heavy-metal ZnS quantum dots with bright blue photoluminescence by a one-step aqueous synthesis; Nanotechnology 2007; 18:205604 doi: 10.1088/09574484/18/20/205604.[Cross Ref]

9. Zheng YG, Yang ZC, Ying JY. Aqueous synthesis of glutathionecapped $\mathrm{ZnSe}$ and $\mathrm{Zn}_{1-\mathrm{x}} \mathrm{Cd}_{\mathrm{x}} \mathrm{Se}$ alloyed quantum dots. Adv Mater. 2007;19(11):1475 doi:10.1002/adma.200601939. [Cross Ref]

10. Lan GY, et al. Photo-assisted synthesis of highly fluorescent $\mathrm{ZnSe(S})$ quantum dots in aqueous solution. J Mater Chem. 2007;17(25):26612666 doi:10.1039/b702469j. [Cross Ref]

11. Zhang $\mathrm{H}$, et al. Hydrothermal synthesis for high-quality CdTe nanocrystals. Adv doi:10.1002/adma.200305653. [Cross Ref

12. Ge JP, et al. Synthesis of CdSe, $\mathrm{ZnSe}$, and $\mathrm{Zn}_{\mathrm{x}} \mathrm{Cd}_{1-\mathrm{x}}$ Se nanocrystals and their silica sheathed core/shell structures. Inorg Chem. 2006;45(13):4922-4927.

10.1021/ic051598k. [PubMed] [Cross Ref

13. Murray CB, Norris DJ, Bawendi MG. Synthesis and characterization of nearly monodisperse $\mathrm{CdE} \quad(\mathrm{E}=$ sulfur, selenium, tellurium) semiconductor nanocrystallites. J Am Chem Soc. 1993;115(19):87068715. doi: 10.1021/ja00072a025. [Cross Ref]

14. Peng ZA, Peng XG. Nearly monodisperse and shape-controlled CdSe nanocrystals via alternative routes: nucleation and growth. J Am Chem Soc. 2002;124(13):3343-3353 doi:10.1021/ja0173167.[PubMed] [Cross Ref]

15. Yang YA, et al. Synthesis of CdSe and CdTe nanocrystals withou precursor injection. Angew Chem Int Ed Engl. 2005;44(41):67126715 doi:10.1002/anie.200502279. [PubMed] [Cross Ref]

16. Ouyang J, et al. Multiple families of magic-sized CdSe nanocrystals with strong bandgap photoluminescence via noninjection one-pot syntheses. J Phys Chem C. 2008;112(36):13805-13811. doi: 10.1021/jp803845n. [Cross Ref]

17. $\mathrm{Yu} \mathrm{K}$, et al. Single-sized CdSe nanocrystals with bandgap photoemission via a non-injection one-pot approach. J Phys Chem C. 2009;113(9):3390-3401. doi: 10.1021/jp809990a. [Cross Ref]

18. Ouyang JY, et al. Photoluminescent colloidal CdS nanocrystals with high quality via non-injection one-pot synthesis in 1-octadecene. J Phys Chem $\quad$ C. 2009; 113(18):7579-7593. doi: 10.1021/jp900252e.[Cross Ref]

19. Liu TY, et al. Non-injection and low-temperature approach to colloida photoluminescent PbS nanocrystals with narrow bandwidth. J Phys Chem C. 2009;113(6):2301-2308 doi:10.1021/jp809171f.[Cross Ref]

20. Ouyang JY, et al. Noninjection, one-pot synthesis of photoluminescent colloidal homogeneously alloyed CdSeS quantum dots. J Phys Chem C. 2009;113(13):5193-5200 doi:10.1021/jp8110138. [Cross Ref]

21. Wang $\mathrm{R}$, et al. Homogeneously-alloyed CdTeSe single-sized nanocrystals with bandgap photoluminescence. J Phys Chem C. 2009;113(9):3402-340 doi:10.1021/jp810325z. [Cross Ref]

22. Wang RB, et al. Magic-sized Cd3P2 II-V nanoparticles exhibiting bandgap photoemission. J Phys Chem C. 2009;113(42):17979-17982 doi:10.1021/jp907642b. [Cross Ref]

23. Nuchter M, et al. Microwave assisted synthesis - a critical technology overview. Green Chem. 2004; 6(3):128-141. doi: 10.1039/b310502d. [Cross Ref] quantum dots for near-infrared fluorescent sensing of

24. Shockley W, Queisser HJ. Detailed balance limit of efficiency of p-n junction solar cells. J Appl Phys. 1961;32(3):510-519 doi:10.1063/1.1736034. [Cross Ref]

25. Johnston KW, et al. Schottky-quantum dot photovoltaics for efficient infrared power conversion. Appl Phys Lett. 2008;92(15):151115-3. doi: 10.1063/1.2912340. [Cross Ref]

26. Tang J, et al. Schottky quantum dot solar cells stable in air under solar illumination. Adv

Mater. 2010;22(12):1398-140 doi:10.1002/adma.200903240. [PubMed] [Cross Ref]

27. Luther JM, et al. Schottky solar cells based on colloidal nanocrystal films. Nano doi:10.1021/nl802476m. [PubMed] [Cross Ref]

28. Ma W, et al. Photovoltaic devices employing ternary $\mathrm{PbS}_{\mathrm{x}} \mathrm{Se}_{1-\mathrm{x}}$ nanocrystals. Nano Lett. 2009;9(4):1699-1703 doi:10.1021/nl900388a. [PubMed] [Cross Ref]

29. [29] Clifford JP, et al. Schottky barriers to colloidal quantum dot films. Appl Phys Lett. 2007; 91(25):253117-3. doi:10.1063/1.2823582. [Cross Ref]

30. Gur I, et al. Air-stable all-inorganic nanocrystal solar cells processed from solution. Science. 2005; doi:10.1126/science.1117908. [PubMed] [Cross Ref]

31. Kamat PV. Quantum dot solar cells. Semiconductor nanocrystals as light harvesters $\dagger$ J Phys Chem C. 2008; 112(48):18737-18753. doi:10.1021/jp806791s. [Cross Ref]

32. Lee HJ, et al. CdSe quantum dot-sensitized solar cells exceeding efficiency $1 \%$ at full-sun intensity. J Phys Chem C. 2008; 112(30):11600-11608. doi:10.1021/jp802572b. [Cross Ref]

33. Achermann $\mathrm{M}$, et al. Energy-transfer pumping of semiconductor nanocrystals using an epitaxial quantum well. Nature. 2004;429(6992):642-646. doi:10.1038/nature02571. [PubMed] [Cross Ref]

34. Sun Q, et al. Bright, multicoloured light-emitting diodes based on quantum dots. Nat Photo

35. X. Gong et al., Nature Photonics. 2016, 10, 253- 257

36. G. J. Supran et al., Adv. Mater. 2015, 27, 1437-1442

37. S. Veldhuis et al., Adv. Mater. 2016, 28(32):6804-34

38. J. Song et al., "Quantum Dot Light-Emitting Diodes Based on Inorganic Perovskite Cesium Lead Halides (CsPbX3)", Adv. Mater. 2015, 27, 7162-7167

39. X. Dai et al., "Solution processed, high performance light emitting diodes based on quantum dots", Nature. 2014, 515, 96-99, doi:10.1038/nature13829 (2014)

40. O. Chen et al., Nature materials. 2013, 12, 445-451

41. L. Protesescu et al., Nano letters. 2015, 15, 3692-3696

42. X. Li et al., Adv. Func. Mater. 2016, 26, 2435-2445

43. T-H Kim et al., MRS bulletin. 2013, 38, 712-720

44. B. Huang et al, Superlattices and Microstructures. 2016, 91, 201-207

45. G.J. Supran et al, MRS Bulletin. 2013, 28, 703-711.

46. G. Konstantatos, Colloidal quantum dot photodetectors. Colloidal Quantum Dot Optoelectronics and Photovoltaics, eds. G. Konstantatos and E. H. Sargent. Published by Cambridge University Press, 2013

47. G. Konstantatos et al., Nature nanotechnology. 2010, 5, 391-40

48. Marat Lutfullin, Lutfan Sinatra and Osman M. Bakr, "Quantum dots for electronics and energy applications", King Abdullah University of Science and Technology, Thuwal, Saudi Arabia

49. Fuhrer M, Kim B, Dürkop T, Brintlinger T. High-mobility nanotube transistor memory. Nano Lett. 2002;2:755-759. doi: 10.1021/nl025577o. [Cross Ref]

50. Ishiwara H. Current status of ferroelectric-gate Si transistors and challenge to ferroelectric-gate CNT transistors. Curr Appl Phys. 2009;9:S2-S6. doi:10.1016/j.cap.2008.02.013. [Cross Ref]

51. Javey A, Guo J, Wang Q, Lundstrom M, Dai H. Ballistic carbon nanotube field-effect transistors. Nature. 2003;424:654-657. doi:10.1038/nature01797. [PubMed] [Cross Ref]

52. Nishio T, Miyato Y, Kobayashi K, Ishida K, Matsushige K, Yamada $\mathrm{H}$. The effect of local polarized domains of ferroelectric P(VDF/TrFE) copolymer thin film on a carbon nanotube field-effect transistor. Nanotechnology. 2008;19:035202. doi:10.1088/09574484/19/03/035202 [PubMed] [Cross Ref]

53. Artukovic E, Kaempgen M, Hecht D, Roth S, Grüner G. Transparent and flexible carbon nanotube transistors. NanoLett. 2005;5:757-760. doi:10.1021/nl050254o. [PubMed] [Cross Ref]

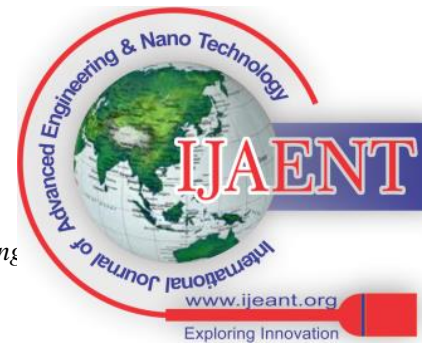




\section{Nanomaterials: Applications in Electronics}

54. Bradley K, Gabriel JCP, Grüner G. Flexible nanotube electronics. Nano Lett. 2003;3:1353-1355. doi: 10.1021/nl0344864. [Cross Ref]

55. [55]Lee JD, Hur SH, Choi JD. Effects of floating-gate interference on NAND flash memory cell operation. IEEE Electron Device Lett. 2002;23:264-266.

56. $\mathrm{Fu} \mathrm{W}, \mathrm{Xu} \mathrm{Z}, \mathrm{Bai} \mathrm{X}, \mathrm{Gu} \mathrm{C}$, Wang E., "Intrinsic memory function of carbon nanotube-based ferroelectric field-effect transistor. Nano Lett. 2009; 9:921-925 doi: 10.1021/nl801656w. [PubMed][Cross Ref]

57. Y Z Long, M M Li, C Gu et al., "Recent advances in synthesis, physical properties and applications of conducting polymer nanotubes and nanofibers," Progress in Polymer Science, vol. 36, no. 10, pp. 14151442, 2011. View at Publisher · View at Google Scholar · View at $\underline{\text { Scopus }}$

58. P. S. Kumar, J. Sundaramurthy, S. Sundarrajan et al., "Hierarchical electrospun nanofibers for energy harvesting, production and environmental remediation," Energy \& Environmental Science, vol. 7 no. 10, pp. 3192-3222, 2014. View at Publisher · View at Google $\underline{\text { Scholar }}$

59. S. Ramakrishna, R. Jose, P. S. Archana et al., "Science and engineering of electrospun nanofibers for advances in clean energy, water filtration, and regenerative medicine," Journal of Materials Science, vol. 45, no. 23, pp. 6283-6312, 2010. View at Publisher - View at Google Scholar · View at Scopus

60. S. Chuangchote, T. Sagawa, and S. Yoshikawa, "Efficient dyesensitized solar cells using electrospun $\mathrm{TiO}_{2}$ nanofibers as a light harvesting layer," Applied Physics Letters, vol. 93, no. 3, Article ID 033310, 2008. View at Publisher · View at Google Scholar $\cdot$ View at Scopus

61. S. Cavaliere, S. Subianto, I. Savych, D. J. Jones, and J. Rozière, "Electrospinning: designed architectures for energy conversion and storage devices," Energy and Environmental Science, vol. 4, no. 12, pp. 4761-4785, 2011. View at Publisher . View at Google Scholar $\cdot$ View at Scopus

62. J. Fang, X. Wang, and T. Lin, "Functional applications of electrospun nanofibers," in Nanofibers_-Production, Properties and Functional Applications, pp. 287-326, InTech, 2011. View at Google Scholar

63. K. Mukherjee, T.-H. Teng, R. Jose, and S. Ramakrishna, "Electron transport in electrospun $\mathrm{TiO}_{2}$ nanofiber dye-sensitized sola cells," Applied Physics Letters, vol. 95, no. 1, Article ID 012101 2009. View at Publisher - View at Google Scholar • View at Scopus

64. Y. Li, D.-K. Lee, J. Y. Kim et al., "Highly durable and flexible dyesensitized solar cells fabricated on plastic substrates: PVDF-nanofiberreinforced $\mathrm{TiO}_{2}$ photoelectrodes," Energy \& Environmental Science, vol. 5, no. 10, pp. 8950-8957, 2012. View at Publisher · View at Google Scholar · View at Scopus

65. H. Krysova, J. Trckova-Barakova, J. Prochazka, A. Zukal, J. Maixner, cells," Catalysis Today, vol. 230, pp. 234-239, 2014. View at Publisher · View at Google Scholar · View at Scopus

66. K. Fujihara, A. Kumar, R. Jose, S. Ramakrishna, and S. Uchida, "Spray deposition of electrospun $\mathrm{TiO}_{2}$ nanorods for dye-sensitized solar cell," Nanotechnology, vol. 18, no. 36, Article ID 365709, 2007. View at Publisher · View at Google Scholar · View at Scopus

67. M. Y. Song, D. K. Kim, K. J. Ihn, S. M. Jo, and D. Y. Kim, "Electrospun $\mathrm{TiO}_{2}$ electrodes for dye-sensitized solar cells," Nanotechnology, vol. 15, no. 12, pp. 1861-1865, 2004. View at Publisher · View at Google Scholar · View at Scopus

68. V. Thavasi, V. Renugopalakrishnan, R. Jose, and S. Ramakrishna, "Controlled electron injection and transport at materials interfaces in dye sensitized solar cells," Materials Science and Engineering R: Reports, vol. 63, no. 3, pp. 81-99, 2009. View at Publisher · View at Google Scholar . View at Scopus

69. Castro Neto A H, Guinea F, Peres N M R, Novoselov K S, Geim A K Rev, "Electronic properties of Graphene", Mod. Phys. 2009, 81, 109

70. Xu, W. G.; Xiao, J. Q.; Chen, Y. F.; Chen, Y. B.; Ling, X.; Zhang, J. Adv. Mater. 2013, 25, 928.

71. Emtsev K V, Bostwick A, Horn K, Jobst J, Kellogg G L, Ley L, McChesney J L, Ohta T, Reshanov S A, Rohrl J, Rotenberg E, Schmid A K, Waldmann D, Weber H B, Seyller T, "Towards wafer-size graphene layers by atmospheric pressure graphitization of silicon carbide", Nat Mater. 2009 Mar; 8(3):203-7 doi: 10.1038/nmat2382 Epub 2009 Feb 8

72. (a) Zhang, Y. B.; Small, J. P.; Pontius, W. V.; Kim, P. "Experimental observation of the quantum Hall effect and Berry's phase in graphene". Appl. Phys. Lett. 2005, 86, 073104. and L. Kavan, "Titania nanofiber photoanodes for dye-sensitized solar

73. Chua, C. K.; Pumera, "Chemical reduction of graphene oxide: a synthetic chemistry viewpoint” M. Chem. Soc. Rev. 2014, 43, 291

74. Design, Synthesis, and Characterization of Graphene-Nanoparticle Hybrid Materials for Bioapplications, Perry T. Yin, Shreyas Shah, Manish Chhowalla, and Ki-Bum Lee

75. M.D Stoller, S Park, Y Zhu, J. An, .S Ruoff, Graphene- based ultracapacitors, Nano Lett. 8(2008) 3498-3502

76. F. Schedin, A.K Geim, SV Morozov,E.W Hill, P Blake, M.I Katsnelson, K.S Novoselov, detection of individual gas molecules absorbed on graphene, Nat Master. 6 (2007) 652-655

77. S.K Lee, B.J Kim, H. Jang, S.C Yoon, C. Lee, B.H Hong, J.A Rogers, J.H Cho, J. H. Ahn, "Stretchable graphene transistors with printed dielectrics and gate electrodes", Nano Lett. 11(2011) 4642-4646

78. Sun S, Gao L, Liu Y. Enhanced dye-sensitized solar cell using graphene-TiO2 photoanode prepared by heterogeneous coagulation, Appl. Phys. Lett 2010; 96:083113-3.

79. Yin Z, Wu S, Zhou X, Huang X, Zhang Q, Boey $F$ et al. Electrochemical deposition of $\mathrm{ZnO}$ nanorods on transparent reduced graphene oxide electrodes for hybrid solar cells, Small 2010; 6:307312 .

80. Wang X, Zhi L, Mullen K., "Transparent, conductive graphene electrodes for dye-sensitized solar cells", Nano Lett 2008; 8:323-327.

81. Guo C., "Layered graphene/quantum dots for photovoltaic devices", Angew, Chem. Int. Ed 2010; 49:3014-3017.

82. Yang N, Zhai J, Wang D, Chen Y, Jiang L., "Two Dimensional Graphene Bridges Enhanced Photoinduced Charge Transport in DyeSensitized Solar Cells", J Am. Chem. Soc. 2010, 4887-894.

83. Khare PS, Yadav R, Swarup A., "RGO-ZnO Nanocomposite Material of Enhanced Absorbance for Solar Energy Conversion”, Int. J Appl. Phys. Math. 2013; 3:95-97.

84. Kim HN, Yoo H, Moon JH., "Graphene-embedded 3D TiO2 inverse opal electrodes for highly efficient dye sensitized solar cells: Morphological characteristics and photocurrent enhancement. Nanoscale 2013; 5:4200- 4204.

85. Tang Y, Lee C, Xu J, Liu Z, Chen Z, He Z et al., "Incorporation of graphenes in nanostructured $\mathrm{TiO} 2$ films via molecular grafting for dyesensitized solar cell application", ACS Nano 2010, 4,3482-3488

86. Yan Wang, Zhiqiang Shi, Yi Huang, Yanfeng Ma, Chengyang Wang, Mingming Chen and Yongsheng Chen, "Supercapacitor Devices Based on Graphene Materials", J. Phys. Chem. C 2009, 113, 1310313107

87. Matt Davenport, "Quantum Dot solar cell hit record efficiency", C\&EN volume 94 issue 28/p.9/Concentrates , Jul 2016

88. Lisa Zyga, "Quantum dot LEDs get brighter, more efficient", Phys.org, Apr 2012

89. Aaron D Franklin, Mathieu Luisier, Shu-Jen Han, George Tulevski, Chris M Breslin, Lynne, Nano Letters 12(2), 758-762, 2012

90. Supriyo Datta 'Nanoelectronic devices - A unified view' To appear in The Oxford Handbook on Nanoscience and Nanotechnology: Frontiers and Advances, eds. A.V. Narlikar and Y.Y. Fu, volume 1, chapter 1

91. Chen et al., Japanese Journal of Applied Physics, vol. 45, no. 4B, pp. 3680-3685, 2006

92. Na, P. S., Park, N., Kim, J., Kim, H., Kong, K. J., Chang, H., \& Lee, J. O. "A field effect transistor fabricated with metallic single-walled carbon nanotubes".( 2006) Fullerenes Nanotubes and Carbon Nanostructures Nanotubes(2-3):141-149 https://doi.org/10.1080/15363830600663438 Y. B. Kim, "Integrated Circuit Design Based on Carbon Nanotube Field Effect Transistor", Transactions on Electrical and Electronic Materials, Vol. 12, No. 5, pp. 175-188, October 25, 2011, pISSN: 1229-7607, eISSN: 2092-7592.

93. Turja Nandy et al., "Analytical distinction between CNTFET based and MOSFET based SRAMs and logic gates", Electrical and Electronics Engineering: An International Journal (ELELIJ) Vol 4, No 3, August 2015

94. IBM news: Kurzweil Digest Oct 2012

95. Yongho Joo, Gerald J. Brady, Michael S. Arnold, and Padma Gopalan, “ Dose-Controlled, Floating Evaporative Self-assembly and Alignment of Semiconducting Carbon Nanotubes from Organic Solvents", Langmuir, 2014, 30 (12), pp 3460-3466, doi: 10.1021/la500162x, Publication Date (Web): March 2, 2014

96. M. Han, B. Özyilmaz, Y. Zhang, and P. Kim, "Energy Band-Gap Engineering of Graphene Nanoribbons," Physical Review Letters, vol. 98, May. 2007, pp.1-4

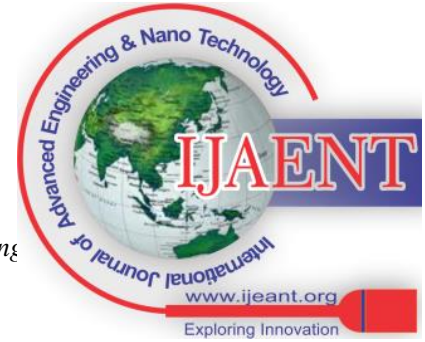


97. X. Li, X. Wang, L. Zhang, S. Lee, and H. Dai, "Chemically derived, ultrasmooth graphene nanoribbon semiconductors.," Science (New York, N.Y.), vol. 319, Feb. 2008, pp. 1229-32

98. J.H. Chen, C. Jang, S. Adam, M.S. Fuhrer, E.D. Williams, and M. Ishigami, "Charged impurity scattering in graphene," Nature Physics, vol. 4, Apr. 2008, pp. 377-381

99. Hongsik Park et al., "High-density integration of carbon nanotubes via chemical self-assembly", Nature Nanotechnology, 2012, DOI: 10.1038/ nnano.2012.189

100. Novoselov K S, Fal'ko V I, Colombo L, Gellert P R, Schwab M G, Kim K, "A roadmap for graphene", Nature 2012, 490, 192

101. Alireza Valizadeh, Haleh Mikaeili, Mohammad Samiei, Samad Mussa Farkhani, Nosratalah Zarghami, Mohammad kouhi, Abolfazl Akbarzadeh, Soodabeh Davaran, "Quantum dots: synthesis, bioapplications, and toxicity”, Nanoscale Research Letters20127:480, https://doi.org/10.1186/1556-276X-7-480

102. Bera D, Qian L, Tseng T-K, Holloway PH: Quantum dots and their multimodal applications: a review. April 2010, Materials 33390(4):2260-2345, DOI: 10.3390/ma3042260

103. Murray CB, Norris DJ, Bawendi MG. Synthesis and characterization of nearly monodisperse $\mathrm{CdE}$ ( $\mathrm{E}=$ sulfur, selenium, tellurium) semiconductor nanocrystallites. J Am Chem Soc. 1993;115(19):87068715. doi: 10.1021/ja00072a025. [CrossRef]

104. Michael Z. Hu, Ting Zhu, "Semiconductor Nanocrystal Quantum Dot Synthesis Approaches Towards Large-Scale Industrial Production for Energy Applications", Nanoscale Res Lett. 2015; 10: 469; PMCID: PMC4670437 doi: [10.1186/s11671-015-1166-y]

105. Schaller, R.; Klimov, V. (2004). "High Efficiency Carrier Multiplication in PbSe Nanocrystals: Implications for Solar Energy Conversion". Physical Review Letters. 92 (18): 186601. arXiv:condmat/0404368. Bibcode:2004PhRvL..92r6601S doi:10.1103/PhysRevLett.92.186601. PMID 15169518.

106. Ellingson, Randy J.; Beard, Matthew C.; Johnson, Justin C.; Yu, Pingrong; Micic, Olga I.; Nozik, Arthur J.; Shabaev, Andrew; Efros, Alexander L. (2005). "Highly Efficient Multiple Exciton Generation in Colloidal PbSe and PbS Quantum Dots" (PDF). Nano Letters. 5 (5): 865-71. Bibcode:2005NanoL...5..865E. doi:10.1021/nl0502672. PMID 15884885.

107. "Quantum Dot Materials Can Reduce Heat, Boost Electrical Output", NREL Press Release, 23 May 2005

108. Colvin VL, Schlamp MC, Alivisatos AP. Light-emitting diodes made from cadmium selenide nanocrystals and a semiconducting polymer. Nature. 1994;370(6488):354-357. doi: 10.1038/370354a0. [CrossRef]

109. Tan Z, et al. Bright and color-saturated emission from blue lightemitting diodes based on solution-processed colloidal nanocrystal quantum dots. Nano Lett. 2007;7(12):3803-3807. doi: 10.1021/nl072370s. [PubMed] [CrossRef]

110. Caruge JM, et al. Colloidal quantum-dot light-emitting diodes with metal-oxide charge transport layers. Nat Photon. 2008;2(4):247-250. doi: 10.1038/nphoton.2008.34. [CrossRef]

111. Slide 1 (tiiciiitm.com)

112. Joo, Yongho, Gerald J Brady, Michael Scott Arnold, and Padma Gopalan. "Dose-controlled, Floating Evaporative Self-assembly and Alignment of Semiconducting Carbon Nanotubes from Organic Solvents", Langmuir, 2014.

113. Shengjie Peng, Guorui Jin Linlin Li, Kai Li , Madhavi Srinivasan, Seeram Ramakrishna, Jun Chen " Multi-functional electrospun nanofibres for advances in tissue regeneration, energy conversion \& storage, and water treatment", Chem Soc Rev. 2016 Mar 7;45(5):1225-41. doi: 10.1039/c5cs00777a.

114. Carbon Nanotube Synthesis (azonano.com)

115. Nanotechnology: Principles and Practice Authors: Kulkarni, Sulabha $\mathrm{K}$.

\section{AUTHOR PROFILE}

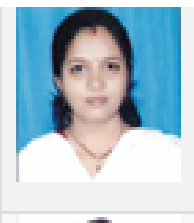

Mrs. Harshada V. Mhetre is studying in Shivaji University, Kolhapur as a Research Scholar student. She is awarded by B.E. (E\&TC) from Pune University, M.Tech. (Electronics Engg.) from Bharati Vidyapeeth University,Pune.

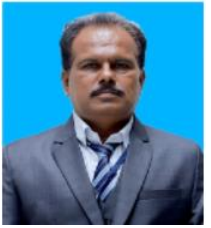

Dr. Yuvraj K. Kanse is recognized guide in Shivaji University, Kolhapur. He is Ph.D. holder in Electronics Engineering. He has published various national, International Journal \& conference papers. Also, he is guide of research scholars in Shivaj University, Kolhapur.

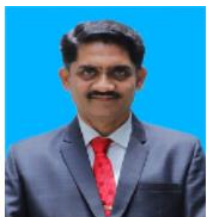

Dr. Suhas S. Patil is recognized guide in Shivaji University, Kolhapur. $\mathrm{He}$ is $\mathrm{Ph} . \mathrm{D}$. holder in Electronics Engineering. He has published various national, International Journal \& conference papers. Also, he is guide of research scholars in Shivaji University, Kolhapur.

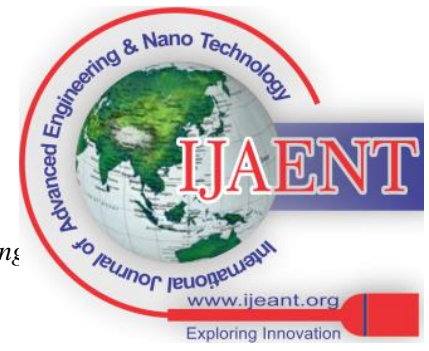

